OPEN ACCESS

Edited by:

Jorge Amil Dias,

Centro Hospitalar de São

João, Portugal

Reviewed by:

Carolina Gutiérrez-Junquera,

Autonomous University of

Madrid, Spain

Marta Lopes Tavares,

Centro Universitário Do

Porto, Portugal

Sonny Chong,

Epsom and St Helier University

Hospitals NHS Trust, United Kingdom

${ }^{*}$ Correspondence:

Xiaodong Guan

guanxiaodong@pku.edu.cn

Qinghong Lu

loveangela100@126.com

Specialty section

This article was submitted to

Pediatric Gastroenterology, Hepatology and Nutrition,

a section of the journa

Frontiers in Pediatrics

Received: 11 March 2021 Accepted: 26 April 2021

Published: 21 May 2021

Citation:

Zhou Y, Xu L, Wushouer H, Yu A, Xu Z, Chen C, Cui Y, Lu Q, Guan X and Shi L (2021) Acid Suppression Use Among Infants in One Tertiary Children's Hospital in China, 2015-2018: A Retrospective Observational Study. Front. Pediatr. 9:679203.

doi: 10.3389/fped.2021.679203

\section{Acid Suppression Use Among Infants in One Tertiary Children's Hospital in China, 2015-2018: A Retrospective Observational Study}

\author{
Yue Zhou ${ }^{1}$, Lina $X u^{2}{ }^{,}$, Haishaerjiang Wushouer ${ }^{1,3}$, Aichen $Y u^{1}$, Ziyue $X u^{1}$, \\ Chaoyang Chen ${ }^{1,4}$, Yimin Cui ${ }^{1,4,5}$, Qinghong $\mathrm{Lu}^{2 *}$, Xiaodong Guan ${ }^{1,3 *}$ and Luwen Shi ${ }^{1,3}$
}

${ }^{1}$ Department of Pharmacy Administration and Clinical Pharmacy, School of Pharmaceutical Sciences, Peking University, Beijing, China, ${ }^{2}$ Department of Pharmacy, Jiangxi Provincial Children's Hospital, Nanchang, China, ${ }^{3}$ International Research Center for Medicinal Administration (IRCMA), Peking University, Beijing, China, ${ }^{4}$ Department of Pharmacy, Peking University First Hospital, Beijing, China, ${ }^{5}$ Institute of Clinical Pharmacology, Peking University, Beijing, China

Clinical guidelines emphasized that physicians should be cautious when prescribing acid suppressions to infants. Histamine-2 receptor antagonists (H2RAs) and proton pump inhibitors (PPIs) are not approved for use in infants aged below 2 years in China. We investigated H2RA/PPI use in infants aged below 2 years hospitalized between 1st January 2015 and 31st December 2018 in a Chinese tertiary children's hospital. Our study observed that H2RAs/PPIs were frequently prescribed with a prevalence of $4.4 \%$ $(7,158 / 162,192)$. The frequency of PPI use was over two-fold than that of H2RA use (71.9\%, 5,148/7,158; 28.1\%, 2,011/7,158). H2RAs/PPIs were commonly used to treat infants without digestive system diseases $(57.5 \%, 4,118 / 7,158)$. Further studies are urgently needed to evaluate the effectiveness and safety of H2RAs/PPIs in infants.

Keywords: acid suppressions, histamine-2 receptor antagonists, proton pump inhibitors, infants, off-label drug use

\section{INTRODUCTION}

Histamine-2 receptor antagonists (H2RAs) and proton pump inhibitors (PPIs) are acid suppressions for gastric acid-related disorders. However, considering the unique characteristics of infant stomach and the different reflux-type symptoms, guidelines emphasized that physicians should be cautious when prescribing H2RAs/PPIs to infants (1-6). The effectiveness of H2RAs/PPIs to treat gastric acid-related disorders in infants was still questioned $(7,8)$. Studies indicated a potential association between H2RAs/PPIs and an increased risk of respiratory tract or gastrointestinal infections, Clostridium difficile infection, and hypomagnesemia in infants (8-11). Nonetheless, H2RAs/PPIs were prescribed to infants frequently and the use had increased dramatically for the past two decades (12-16). Up to now, H2RAs/PPIs are not approved for children in China. Though previous studies highlighted the overuse of PPI medication in adults and the multiple potentially serious side effects (17-19), few studies targeted H2RA/PPI off-label use in infants. Hence, we described H2RA/PPI off-label use trends in infants, and evaluate the association between patient characteristics and diagnoses with H2RA/PPI selection. 


\section{THE TREND OF H2RA/PPI USE IN CHINA}

We calculated the prevalence of H2RA/PPI use (measured by the percentage of admissions treated with H2RAs/PPIs of all admissions) and the frequency of H2RA/PPI use (measured by the number of admissions treated with H2RAs/PPIs) from inpatients aged below 2 years between 1st January 2015 and 31st December 2018 in a tertiary children's hospital in China. Overall, of 162,192 admissions of patients aged below 2 years in the databases during the study period, 7,158 (4.4\%) admissions of the infants treated with H2RAs/PPIs were included. The frequency of PPI use was over 2-fold than that of H2RA use (71.9\%, 5,148/7,158; 28.1\%, 2,011/7,158). Omeprazole and Cimetidine were the most commonly prescribed PPI and H2RA, respectively $(69.6 \%, 4,981 / 7,158 ; 28.1 \%, 2,010 / 7,158)$. During the 4 -year study period, the prevalence of total H2RA/PPI use was $4.3 \%, 4.4 \%$, $4.6 \%$, and $4.4 \%$, respectively. The prevalence of PPI use increased from $2.8 \%$ to $3.5 \%$ while H2RA use decreased from $1.5 \%$ to $0.9 \%$ (Figure 1, Supplementary Table 1).

\section{FACTORS ASSOCIATED WITH H2RA/PPI SELECTION}

The factors associated with H2RA/PPI selection included characteristics and diagnoses of the patients. Characteristic data was retrieved from the hospital medication records, including the admission number of the patients, time of admission, gender, age, medical insurance, diagnoses, medication information, and the number of admissions of patients aged below 2 years. The diagnoses in the hospital were coded using the International Statistical Classification of Diseases, 10th Revision (ICD-10) diagnostic codes (20). The logistic regression analyses were conducted and odds ratios (ORs) and estimates were presented with their 95\% confidence intervals (CIs). The regression demonstrated infants aged above 28 days were more likely to be prescribed PPIs than H2RAs (OR $=21.6,95 \%$ CI 17.9-26.1, $P$ $<0.001$; OR $=7.6,95 \%$ CI 6.3-9.2, $P<0.001)$. Infants covered by the New Rural Cooperative Medical Insurance (NRCMS) or without medical insurance were more likely to use H2RAs than PPIs $(\mathrm{OR}=0.7,95 \%$ CI $0.6-0.9, P<0.001$; OR $=0.8,95 \%$ CI $0.7-0.9, P=0.001)$. Compared with H2RAs, there was a positive correlation between diagnoses including digestive system diseases and PPI use $(\mathrm{OR}=2.0,95 \% \mathrm{CI} 1.8-2.3, P<0.001)$ (Table 1).

\section{DISCUSSION}

We observed that although H2RAs/PPIs were not approved in China for infants, they were frequently prescribed for the population, commonly being used to treat the infants without digestive system diseases. Compared to placebo, H2RAs/PPIs possess uncertain effectiveness in infants. Meanwhile, H2RAs/PPIs could induce infections through changing the stomach acidity that functioned as the barrier to detrimental pathogens through the gastrointestinal tract host defense system $(11,21)$. Evidences in adults also highlighted that long-term PPI use was associated with adverse events including bone fracture, renal disease, cardiac disease, etc. (22). Considering the uncertain effectiveness and potential safety problems of H2RAs/PPIs, more cautions should be taken when prescribing them for the younger population.

The trend of H2RA/PPI use in the sample hospital was relatively stable over time, and the prevalence of PPI use was higher than that of H2RA use. Studies found PPIs were superior to H2RAs in symptom control, such as higher rates of healing of erosive or histologic esophagitis (23-26). Guidelines recommended PPIs as a first-line treatment for server gastric acid-related diseases in infants while H2RAs were suggested when PPIs were unavailable or contra-indicated or the symptom was mild to moderate $(5,27)$. This may explain the observation of higher frequency of PPI use in our study. Although PPIs were considered to offer advantages over H2RAs in the pediatric population, we observed that H2RAs were still used in nearly one-third of the infants. The infants without medical insurance or covered by NRCMS were more likely to be prescribed with H2RAs. Healthcare expenditure of PPIs was higher than that of H2RAs in the pediatric population (28). Different from their counterparts covered by the Urban Residents' Basic Medical Insurance (a more beneficial schemes), infants covered by NRCMS or without medical insurances were more likely subjected to healthcare expenditure burden and tended to be treated with H2RAs (29).

The main indications of H2RAs/PPIs approved were to treat gastroesophageal reflux disease and to heal and prevent gastroduodenal ulcers. However, our study observed the proportion of admissions diagnosed without digestive system diseases, over one-half, was unexpected; the respiratory system diseases were the most common diagnoses. Respiratory system diseases, such as asthma and acute upper respiratory tract infection (URTI) are common disorders in children. Gastroesophageal reflux is prevalent among children suffering from asthma (5, 30-32). However, there were no significant differences in asthma symptom remission or pulmonary function improvement but a higher risk of adverse events between H2RAs/PPIs vs. placebo (33-35). Moreover, studies found that H2RAs could exert potent modulatory effects on the cells with innate and adaptive immunity to defend against the virus (36). Although the finding could support the acute URTI treatment with H2RAs, more evidence of effectiveness and safety are required, especially when using in infants. Additionally, we presumed H2RAs/PPIs might also be used as an empiric prophylactic therapy in infants as the infants tended to be seriously ill when being admitted to the hospitals. Nevertheless, the appropriateness of the clinical practices is still questioned. Further studies are urgently requested to evaluate the effectiveness and safety of these practices.

The common off-label prescriptions of H2RA/PPI prescription in Chinese infants in our study warned that regulation of H2RA/PPI use was required. It would be useful and necessary to educate and inform physicians about the misuse and potential adverse effects of H2RAs/PPIs in infants. Moreover, given the uncertainty of effectiveness and safety of H2RAs/PPIs in infants, clinicians had better try alternative therapies or 


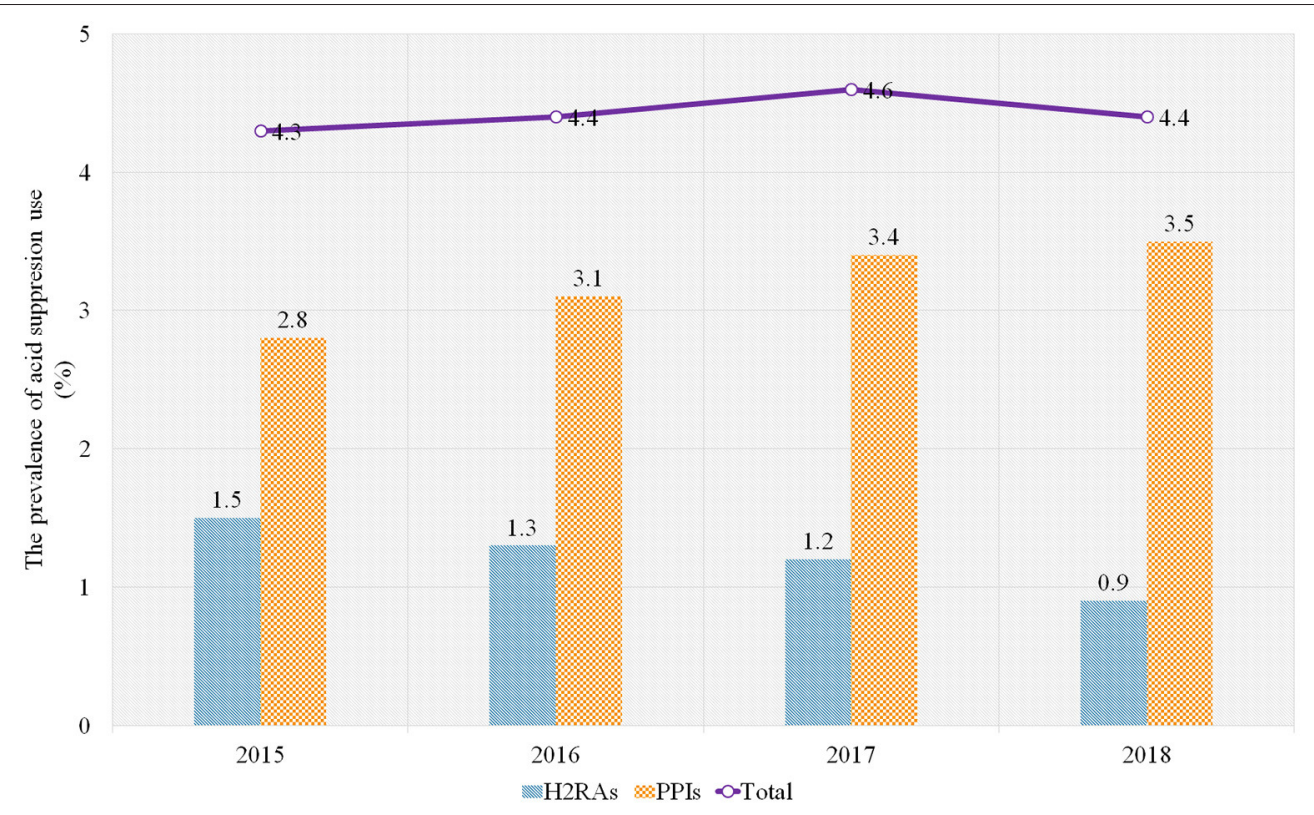

FIGURE 1 | The prevalence of H2RA/PPI use in the sample hospital, 2015-2018. PPIs, proton pump inhibitors; H2RAs, Histamine-2 receptor antagonists.

TABLE 1 | Characteristics and diagnoses of patients prescribed PPIs compared with those prescribed H2RAs.

\begin{tabular}{|c|c|c|c|c|}
\hline \multirow[t]{2}{*}{ Variables } & \multicolumn{4}{|c|}{$\begin{array}{c}\text { Inpatient } \\
N=7,158, n(\%)\end{array}$} \\
\hline & PPIs Cohort & H2RAs Cohort & $\begin{array}{l}\text { PPIs vs. H2RAs } \\
\text { OR (95\% Cl) }\end{array}$ & $P$-value \\
\hline \multicolumn{5}{|l|}{ Gender } \\
\hline Male & $3,339(46.6)$ & $1,282(17.9)$ & 1.0 (reference) & \\
\hline$<28$ days & $230(3.2)$ & $798(11.1)$ & 1.0 (reference) & \\
\hline (28days, 1 year) & $3,568(49.8)$ & $612(8.5)$ & $21.6(17.9-26.1)$ & $<0.001$ \\
\hline (1 year, 2 years) & $1,350(18.9)$ & $600(8.4)$ & $7.6(6.3-9.2)$ & $<0.001$ \\
\hline \multicolumn{5}{|l|}{ Insurance } \\
\hline URBMI & $1,675(23.4)$ & $403(5.6)$ & 1.0 (reference) & \\
\hline No digestive system diseases & 2,807 (39.2) & $1,311(18.3)$ & 1.0 (reference) & \\
\hline With digestive system diseases & $2,341(32.7)$ & $699(9.8)$ & $2(1.8-2.3)$ & $<0.001$ \\
\hline
\end{tabular}

URBMI, the Urban Residents' Basic Medical Insurance; NRCMS, the New Rural Cooperative Medical Insurance; PPIs, proton pump inhibitors; H2RAs, Histamine-2 receptor antagonists; $\mathrm{O}$, odds ratio; $\mathrm{Cl}$, confidence interval.

interventions in the first place. These may include considering conservative means, taking anti-reflux precautions, reducing aerophagy, using hypoallergenic formulae, consideration of Eosinophilic Esophagitis, reassurance, etc. (37).

Our study, however, was subjected to several limitations. Firstly, as a retrospective observational study, our analyses were based on the hospital medication records. The database included information on patient characteristics, diagnoses and drug use. This limited our study perspectives to explore the underlying factors associated with H2RA/PPI prescribing and the explanation for $\mathrm{H} 2 \mathrm{RAs} / \mathrm{PPIs}$ prescribed to treat patients without digestive system diseases. Secondly, characteristic and diagnosis data of admissions of patients not using H2RAs/PPIs was unobtainable. This may limit the analysis to figure out the factors associated with H2RA/PPI use in the target population. Thirdly, the bias derived from missing data or recording errors 
in diagnoses could lead the proportion of admissions diagnosed without digestive system diseases overestimated. Finally, as a hospital-based study in a single center, it may not be generalized to other suppliers of the pediatric medical services. However, based on the data retrieved from one of the largest children's hospitals in China, we believed that the findings could reflect the problem of H2RA/PPI use among infants and could be representative to some extent.

In conclusion, our study showed that although not approved for infants in China, H2RA/PPI prescription was common in hospitalized infants, even those admitted with non-digestive diseases. The findings highlighted the necessity of optimizing and regulating H2RA/PPI use. Further studies, such as clinical trials, are urgently needed to evaluate the effectiveness and safety of H2RAs/PPIs in infants.

\section{DATA AVAILABILITY STATEMENT}

The data analyzed in this study is subject to the following licenses/restrictions: the datasets analyzed for this study are available from the corresponding authors on a reasonable request. Requests to access these datasets should be directed to Xiaodong Guan, guanxiaodong@pku.edu.cn.

\section{ETHICS STATEMENT}

The studies involving human participants were reviewed and approved by Ethics Committee of Peking University Health Science Center, Beijing, China. Written informed consent from the participants' legal guardian/next of kin was not required

\section{REFERENCES}

1. Jadcherla SR. Gastroesophageal reflux in the neonate. Clin Perinatol. (2002) 29:135-58. doi: 10.1016/S0095-5108(03)00068-X

2. Jadcherla SR, Parks VN, Peng J, Dzodzomenyo S, Fernandez S, Shaker $\mathrm{R}$, et al. Esophageal sensation in premature human neonates: temporal relationships and implications of aerodigestive reflexes and electrocortical arousals. Am J Physiol Gastrointest Liver Physiol. (2012) 302:G134-44. doi: 10.1152/ajpgi.00067.2011

3. Jadcherla SR, Duong HQ, Hoffmann RG, Shaker R. Esophageal body and upper esophageal sphincter motor responses to esophageal provocation during maturation in preterm newborns. J Pediatr. (2003) 143:31-8. doi: 10.1016/S0022-3476(03)00242-7

4. Jadcherla SR, Gupta A, Fernandez S, Nelin LD, Castile R, Gest AL, et al. Spatiotemporal characteristics of acid refluxate and relationship to symptoms in premature and term infants with chronic lung disease. Am J Gastroenterol. (2008) 103:720-8. doi: 10.1111/j.1572-0241.2007.01748.x

5. Rosen R, Vandenplas Y, Singendonk M, Cabana M, DiLorenzo C, Gottrand $\mathrm{F}$, et al. Pediatric gastroesophageal reflux clinical practice guidelines: joint recommendations of the North American Society for Pediatric Gastroenterology, Hepatology, and Nutrition and the European Society for Pediatric Gastroenterology, Hepatology, and Nutrition. $J$ Pediatr Gastroenterol Nutr. (2018) 66:516-54. doi: 10.1097/MPG.0000000000001889

6. Wang G, Li Z, Xie X, Xu D. Expert consensus on the rational use of proton pump inhibitors for children (2019 edition). Chin J Practical Pediatrics. (2019) 34:977-81. doi: 10.19538/j.ek2019120602

7. Gieruszczak-Bialek D, Konarska Z, Skorka A, Vandenplas Y, Szajewska H. No effect of proton pump inhibitors on crying and irritability in infants: systematic review of randomized controlled trials. J Pediatr. (2015) 166:767U1086. doi: 10.1016/j.jpeds.2014.11.030 to participate in this study in accordance with the national legislation and the institutional requirements.

\section{AUTHOR CONTRIBUTIONS}

XG, QL, and YC: conceptualization. YZ, LX, and CC: methodology. XG and LS: validation. YZ, HW, AY, and ZX: formal analysis. XG and QL: resources and supervision. YZ, HW, and AY: data curation. YZ: writing-original draft preparation and project administration. XG: writing - review and editing. XG and YZ: funding acquisition. All authors read and approved the final manuscript.

\section{FUNDING}

This work was supported by Peking University Medicine Seed Fund for Interdisciplinary Research and the Fundamental Research Funds for the Central Universities [Grant Number BMU2018MX010]; Student Innovation Fund by School of Pharmaceutical Sciences, Peking University [Grant Number: not applicable]. The funders had no role in the design of the study and collection, analysis, and interpretation of data and in writing the manuscript.

\section{SUPPLEMENTARY MATERIAL}

The Supplementary Material for this article can be found online at: https://www.frontiersin.org/articles/10.3389/fped. 2021.679203/full\#supplementary-material

8. van der Pol R, Langendam M, Benninga M, van Wijk M, Tabbers M. Efficacy and safety of histamine-2 receptor antagonists. JAMA Pediatr. (2014) 168:94754. doi: 10.1001/jamapediatrics.2014.1273

9. Santos VS, Freire MS, Santana RNS, Martins-Filho PRS, Cuevas LE, Gurgel RQ. Association between histamine-2 receptor antagonists and adverse outcomes in neonates: a systematic review and metaanalysis. PLoS ONE. (2019) 14:e0214135. doi: 10.1371/journal.pone.02 14135

10. Chang TH, Hsu WY, Yang TI, Lu CY, Hsueh PR, Chen JM, et al. Increased age and proton pump inhibitors are associated with severe Clostridium difficile infections in children. J Microbiol Immunol Infect. (2018) 53:578-84. doi: 10.1016/j.jmii.2018.09.002

11. Cohen S, Bueno de Mesquita M, Mimouni FB. Adverse effects reported in the use of gastroesophageal reflux disease treatments in children: a 10 years literature review. Br J Clin Pharmacol. (2015) 80:200-8. doi: 10.1111/bcp.12619

12. Blank M-L, Parkin L. National study of off-label proton pump inhibitor use among New Zealand infants in the 1st year of life (2005-2012). J Pediatr Gastroenterol Nutr. (2017) 65:179-84. doi: 10.1097/MPG.00000000000 01596

13. Slaughter JL, Stenger MR, Reagan PB, Jadcherla SR. Neonatal histamine2 receptor antagonist and proton pump inhibitor treatment at United States Children's Hospitals. J Pediatr. (2016) 174:63-70.e3. doi: 10.1016/j.jpeds.2016.03.059

14. Barron JJ, Tan H, Spalding J, Bakst AW, Singer J. Proton pump inhibitor utilization patterns in infants. $J$ Pediatr Gastroenterol Nutr. (2007) 45:421-7. doi: 10.1097/MPG.0b013e31812 e0149

15. Illueca $M$, Alemayehu $B$, Shoetan N, Yang $H$. Proton pump inhibitor prescribing patterns in newborns and infants. $J$ Pediatric 
Pharmacol Therapeut. (2014) 19:283-7. doi: 10.5863/1551-6776-19. 4.283

16. De Bruyne P, Christiaens T, Vander Stichele R, Van Winckel M. Changes in prescription patterns of acid-suppressant medications by Belgian pediatricians: analysis of the national database, [1997-2009]. J Pediatr Gastroenterol Nutr. (2014) 58:220-5. doi: 10.1097/MPG.0b013e3182a3b04e

17. Zeng W, Finlayson AE, Shankar S, de Bruyn W, Godman B. Prescribing efficiency of proton pump inhibitors in China: influence and future directions. BMC Health Serv Res. (2015) 15:11. doi: 10.1186/s12913-014-0638-6

18. Luo H, Fan Q, Xiao S, Chen K. Changes in proton pump inhibitor prescribing trend over the past decade and pharmacists' effect on prescribing practice at a tertiary hospital. BMC Health Serv Res. (2018) 18:537. doi: 10.1186/s12913-018-3358-5

19. Katz PO. The proton pump inhibitor is not working: assess don't guess. Gastroenterology. (2021) 160:19-20. doi: 10.1053/j.gastro.2020.10.043

20. WHO. ICD-10 Version. (2016). Available online at: https://icd.who.int/ browse10/2016/en (accessed January 19, 2020).

21. Levy EI, Hoang DM, Vandenplas Y. The effects of proton pump inhibitors on the microbiome in young children. Acta Paediatr. (2020) 109:1531-8. doi: 10.1111/apa.15213

22. Reimer C. Safety of long-term PPI therapy. Best Pract Res Clin Gastroenterol. (2013) 27:443-54. doi: 10.1016/j.bpg.2013.06.001

23. Katz PO, Gerson LB, Vela MF. Guidelines for the diagnosis and management of gastroesophageal reflux disease. Am J Gastroenterol. (2013) 108:308-28. doi: 10.1038/ajg.2012.444

24. Cremonini F, Ziogas DC, Chang HY, Kokkotou E, Kelley JM, Conboy L, et al. Meta-analysis: the effects of placebo treatment on gastrooesophageal reflux disease. Aliment Pharmacol Ther. (2010) 32:29-42. doi: $10.1111 / j .1365-2036.2010 .04315 . x$

25. Chiba N, De Gara CJ, Wilkinson JM, Hunt RH. Speed of healing and symptom relief in grade II to IV gastroesophageal reflux disease: a meta-analysis. Gastroenterology. (1997) 112:1798-810. doi: 10.1053/gast.1997.v112.pm9178669

26. Labenz J, Malfertheiner P. Treatment of uncomplicated reflux disease. World J Gastroenterol. (2005) 11:4291-9. doi: 10.3748/wjg.v11.i28.4291

27. Ruigómez A, Kool-Houweling LMA, García Rodríguez LA, Penning-van Beest FJA, Herings RMC. Characteristics of children and adolescents first prescribed proton pump inhibitors or histamine-2-receptor antagonists: an observational cohort study. Curr Med Res Opin. (2017) 33:2251-9. doi: 10.1080/03007995.2017.1336083

28. Kothari S, Nelson SP, Wu EQ, Beaulieu N, McHale JM, Dabbous OH. Healthcare costs of GERD and acid-related conditions in pediatric patients, with comparison between histamine-2 receptor antagonists and proton pump inhibitors. Curr Med Res Opin. (2009) 25:2703-9. doi: 10.1185/03007990903307755
29. Meng QY, Yang HW, Chen W, Sun Q, Liu XY. People's Republic of China Health System Review. Manila: World Health Organization. Regional Office for the Western Pacific (2015).

30. Tucci F, Resti M, Fontana R, Novembre E, Lami CA, Vierucci A. Gastroesophageal reflux and bronchial asthma: prevalence and effect of cisapride therapy. J Pediatr Gastroenterol Nutr. (1993) 17:265-70. doi: 10.1097/00005176-199310000-00006

31. Cinquetti M, Micelli S, Voltolina C, Zoppi G. The pattern of gastroesophageal reflux in asthmatic children. J Asthma. (2002) 39:135-42. doi: 10.1081/JAS-120002194

32. Hancox RJ, Poulton R, Taylor DR, Greene JM, McLachlan CR, Cowan JO, et al. Associations between respiratory symptoms, lung function and gastrooesophageal reflux symptoms in a population-based birth cohort. Respir Res. (2006) 7:142. doi: 10.1186/1465-9921-7-142

33. Holbrook JT, Wise RA, Gold BD, Blake K, Brown ED, Castro M, et al. Lansoprazole for children with poorly controlled asthma: a randomized controlled trial. JAMA. (2012) 307:373-81. doi: 10.1001/jama.2011.2035

34. Littner MR, Leung FW, Ballard ED 2nd, Huang B, Samra NK. Effects of 24 weeks of lansoprazole therapy on asthma symptoms, exacerbations, quality of life, and pulmonary function in adult asthmatic patients with acid reflux symptoms. Chest. (2005) 128:1128-35. doi: 10.1378/chest.128. 3.1128

35. American Lung Association Asthma Clinical Research Centers, Mastronarde JG, Anthonisen NR, Castro M, Holbrook JT, Leone FT, et al. Efficacy of esomeprazole for treatment of poorly controlled asthma. N Engl J Med. (2009) 360:1487-99. doi: 10.1056/NEJMoa0806290

36. Jafarzadeh A, Nemati M, Khorramdelazad H, Hassan ZM. Immunomodulatory properties of cimetidine: its therapeutic potentials for treatment of immune-related diseases. Int Immunopharmacol. (2019) 70:156-66. doi: 10.1016/j.intimp.2019.02.026

37. Kuhn BR, Young AJ, Justice AE, Chittoor G, Walton NA. Infant acid suppression use is associated with the development of eosinophilic esophagitis. Dis Esophagus. (2020) 33:doaa073. doi: 10.1093/dote/doaa073

Conflict of Interest: The authors declare that the research was conducted in the absence of any commercial or financial relationships that could be construed as a potential conflict of interest.

Copyright (๔ 2021 Zhou, Xu, Wushouer, Yu, Xu, Chen, Cui, Lu, Guan and Shi. This is an open-access article distributed under the terms of the Creative Commons Attribution License (CC BY). The use, distribution or reproduction in other forums is permitted, provided the original author(s) and the copyright owner(s) are credited and that the original publication in this journal is cited, in accordance with accepted academic practice. No use, distribution or reproduction is permitted which does not comply with these terms. 